Eur J Clin Chem Clin Biochem

1995; 33:497-501

(c) 1995 Walter de Gruyter \& Co.

Berlin - New York

\title{
An Automated Enzymatic Inulin Assay, Capable of Full Sinistrin Hydrolysis ${ }^{1}$ )
}

\author{
By Charles P. R. Soper ${ }^{1}$, Michael R. Bending ${ }^{1}$ and Jeffrey L. Barron ${ }^{2}$ \\ 1 Renal Unit \\ 2 Chemical Pathology Department \\ St. Helier Hospital, Carshalton, Surrey, United Kingdom
}

(Received March 1/May 23, 1995)

\begin{abstract}
Summary: Renal inulin clearance remains the standard by which other methods of measuring glomerular filtration rate are judged. A fully automated enzymatic assay capable of use with linear configuration inulin was recently published (Summerfield AL, et al. Clin Chem 1993; 39:2333-7). Sinistrin, a readily soluble preparation of polyfructan with side branching, is more suitable for clinical use and far more widely used in Europe. By modifying the incubation phase of samples with inulinase, incorporating a kinetic modification to the method of fructose analysis, and increasing the buffer strengths, we report a fully automated system, with minimal sample prehandling capable of complete sinistrin hydrolysis, and adapted for use on the Cobas Mira.
\end{abstract}

\section{Introduction}

The measurement of inulin clearance as a marker of glomerular filtration rate provides the most accurate assessment of renal function. It is subject neither to extra renal metabolism, nor tubular handling, not bound by plasma proteins and capable of free passage through the glomerular basement membrane (1).

Its clinical use has been restricted by several difficulties. Firstly, the insolubility of standard inulin (linear configuration (1,2-linked) polyfructan) renders its use for patient injection difficult. Secondly, the acid hydrolysis of inulin prior to assaying liberated fructose requires considerable laboratory time, especially when concentrated and corrosive reagents are used for the additional purpose of deproteination. Finally colorimetric determination of fructose is not specific (2).

Recent modifications have incorporated the use of an enzymatic assay for fructose, either to the endpoint of substrate consumption, (using Bergmeyer's original combination of hexokinase, glucose-6-phosphate dehy-

1) This work was supported by a grant from the St Helier Research Trust Fund. drogenase and phosphoglucose isomerase) (3) or similar combinations (4), or more suitable for automation a kinetic assay based on sorbitol dehydrogenase $\left.(5)^{2}\right)$.

The use of commercially available synergistic combination of exo- and endo-inulinases ${ }^{2}$ ) has enabled a fully automated enzymatic assay (6). Our own trials of this method worked well with linear configuration inulin, once adapted to employ a kinetic assay for fructose. This adaptation is more suitable to a reaction which results in a small free energy change, leaving a substantial quantity of substrate in equilibrium with product. This modification has also recently been reported by the same group (7).

Sinistrin is a branched polyfructan first reported by Schmeideberg in 1879 (see fig. 1). Its natural source is as an energy storage compound in the bulb of the North

\footnotetext{
2) Enzymes

Novozym 230, a synergistic combination of inulinases:

Exoinulinase:

2,1- $\beta$ - $D$-Fructan fructanhydrolase EC 3.2.1.7

Endoinulinases:

Fructan- $\beta$-fructosidase EC 3.2.1.80

Indicator reaction catalyzed by:

Sorbitol dehydrogenase EC 1.1.1.14.
} 


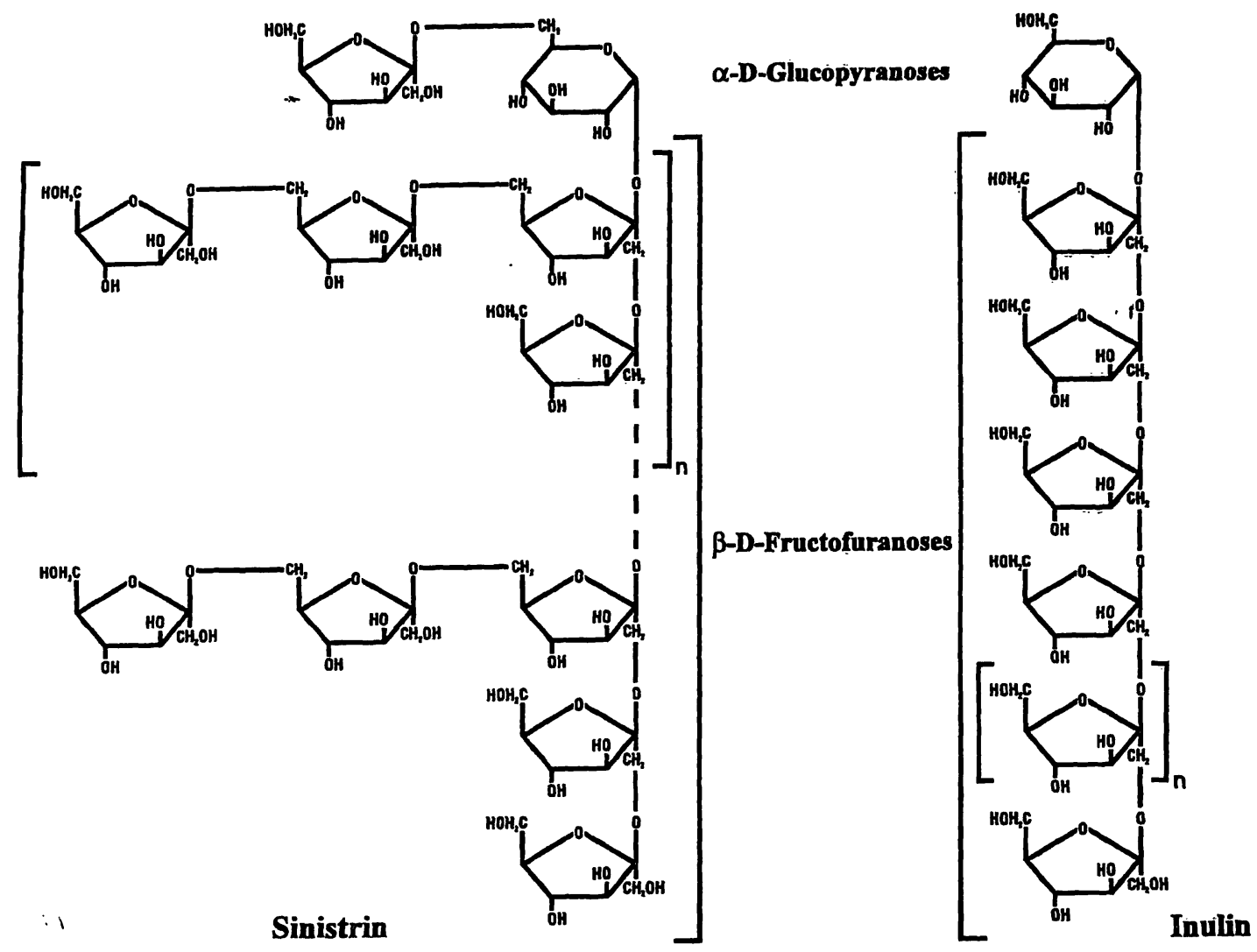

Fig. 1 The structure of sinistrin, consisting of a linear 1,2-linked $\beta$ - $D$-fructose polymer backbone with two or more 2,6-linked levanbiose side chains.

African root vegetable Red Squill, Urginea maritima. Its greater solubility allows far greater ease of handling and preparation for injection for clearance studies. Its degree of polymerisation, consequent relative molecular mass, and equivalent maximum radius from hydrodynamic studies (8) indicate a satisfactory permeability through the glomerular basement membrane, confirmed in subsequent clinical studies (9).

Sinistrin has proved considerably less amendable to enzymatic cleavage than linear inulin, we report a fully automated method capable of complete sinistrin hydrolysis.

\section{Materials and Methods}

\section{Specimens}

Plasma samples were taken as part of inulin infusion clearance examinations from healthy volunteers, its use has already been well described $(10,11)$. This method of analysis of inulin clearance is more suitable in patients with normal or high glomerular filtration rates such as the diabetic hyperfiltering patients we are studying, being less prone to errors from delay to steady state inulin concentration, and delayed equilibration with muscle and fascial tissue compartments. It entails the administration of a bolus dose of sinistrin proportionate to volume of distribution, and a continuous infusion at a rate anticipated to bring the serum steady state concentration to a predetermined target, calculated from previous estimates of clearance. Two samples are taken from the contralateral arm of semirecumbent subjects $2 \mathrm{~h}$ after commencement of the infusion. Together with a sample of the infusate these are analysed for fructan content. Confirmation of steady state is sought by comparison of the 110 with 120 min polyfructan concentration.

\section{Reagents}

Novozym $230^{2}$ ), a synergistic combination of inulinases (EC 3.2.1.7), with reported activity $1.8 \mathrm{MU} /$, was obtained as a liquid concentrate from Novo Nordisk Enzyme Process Division. Sorbitol dehydrogenase (EC 1.1.1.14) as lyophilisate, preweighed $2 \mathrm{mg}$ NADH vials, crystalline fructose, and three natural source inulin preparations (Dahlia Tuber, Dahlia variabilis, Chicory Root, Cichorium intybus, and Jerusalem Artichoke, Helianthus tuberosus) were obtained from Sigma Chemical Co. Ltd. (Poole, Dorset). Sinistrin (Inutest ${ }^{\mathrm{TM}}$ ) was obtained from Laevosan-Gesellschaft, (Linz, Austria) in pharmaceutical grade vials for clinical use.

\section{Methods}

We adapted the previously described method (6) for use on a Cobas Mira (Roche Diagnostic Systems, Welwyn, UK), incorporating a $1250 \mathrm{~s}$ predilution phase, a shorter path length for colorimetry, based on a kinetic analysis of the conversion of fructose to sorbitol, and two fructose standards for calibration with each run. The Mira programme is given in table 1 .

Serum samples were stored at $4{ }^{\circ} \mathrm{C}$ for up to one week, or frozen and kept at $-20^{\circ} \mathrm{C}$ for up to 3 months. Urine and infusate samples were diluted twenty-fold in radioimmunoassay grade bovine serum albumin, $40 \mathrm{~g} / \mathrm{l}$ before the assay.

A $150 \mu \mathrm{l}$ aliquot of Novozym 230 was diluted in $5 \mathrm{ml}$ of 500 $\mathrm{mmol} / \mathrm{l}$ sodium dihydrogen phosphate buffer at $\mathrm{pH} 4.5$ to form the dilution solution. The final concentration of the inulinases being $40.5 \mathrm{kU} / \mathrm{l}$. The sorbitol dehydrogenase was dissolved in $1 \mathrm{~mol} / 1$ hydroxyethyl piperazineethanesulphonic acid (HEPES) buffer, $\mathrm{pH}$ 7.7 , at $4 \mathrm{kU} / \mathrm{h}$. The final reaction concentration being 0.53 units in 
Tab. 1 Cobas Mira Programme (for detailed explanation see the manufacturer's instructions):

\begin{tabular}{ll}
\hline Test INU (Inulinases present) & Test INA (Inulinases Absent) \\
\hline Measurement Mode: Absorb & Measurement Mode: Absorb \\
Reaction Mode: D-R-S & Reaction Mode: D-R-S \\
Calibration Mode: Slope Avg & Calibration Mode: Slope Avg \\
Reagent Blank: Reag/Sol & Reagent Blank: Reag/Sol \\
Cleaner: No & Cleaner: No
\end{tabular}

Wavelength: $340 \mathrm{~nm}$

Decimal Posn: 1

Unit: $\mathrm{mg} / \mathrm{l}$

\section{Analysis}

Dilution Name: $\mathbb{N I}$

Factor: 4.00

Time: $1250 \mathrm{~s}$

Std: Factor

\section{Sample Cycle: 1}

Volume: $50.0 \mu \mathrm{l}$

Dilution Name: $\mathrm{H}_{2} \mathrm{O}$

Volume: $15.0 \mu \mathrm{l}$

Reagent Cycle: 1

Volume: $133 \mu \mathrm{l}$

Reac. Direction: Decrease

Check: On

Convers. Factor: 1.00000

Offset: 0.00000

Test Range Low: $0.0 \mathrm{mg} / \mathrm{l}$

High: $400.0 \mathrm{mg} / \mathrm{l}$

Number Of Steps: 1

Calc. Step A: Endpoint

Readings First: 4 Last: 19

\section{Wavelength: $340 \mathrm{~nm}$ \\ Decimal Posn: 1}

Unit: $\mathrm{mg} / 1$

Analysis
Dilution Name: INO
Factor: 4.00
Time: No
Std: Factor

Sample Cycle: 1

Volume: $50.0 \mu \mathrm{l}$

Dilution Name: $\mathrm{H}_{2} \mathrm{O}$

Volume: $15.0 \mu \mathrm{l}$

Reagent Cycle: 1

Volume: $133 \mu \mathrm{l}$

Reac. Direction: Decrease

Check: On

Convers. Factor: 1.00000

Offset: 0.00000

Test Range Low: $0.0 \mathrm{mg} / 1$

High: $100.0 \mathrm{mg} / 1$

Number Of Steps: 1

Calc. Step A: Endpoint

Readings First: 4 Last: 19

Calibration Interval: Each Run

Blank Sol-Pos: 7

Calibration Interval: Each Run

Blank Sol-Pos: 8

Standard Pos: 1

Std-1; $200 \mathrm{mg} / 1$

Std-2; $200 \mathrm{mg} / 1$

Deviation: $1.5 \%$

Standard Pos: 1

Std-1; $200 \mathrm{mg} / \mathrm{l}$

Std-2; $200 \mathrm{mg} / 1$

Deviation: $1.5 \%$

\begin{tabular}{lll}
\hline Ratios & \multicolumn{2}{l}{ Racks Reagent 10} \\
\hline TING & \multicolumn{2}{c}{ Rack Posn: } \\
Test & 1 & INI* \\
A: INU & 2 & INU \\
B: INI* & 3 & INO** \\
Decimal Posn: 1 & 4 & INA \\
Unit: mg/l & & \\
Formula A-B & & \\
Factor: 1.0 & &
\end{tabular}

* $\mathrm{INI}=$ Diluent for INU (with inulinases)

** INO = Diluent for INA (no inulinases)

$198 \mu \mathrm{l}$. A sample of $6 \mathrm{ml}$ of this preparation was added to a $2 \mathrm{mg}$ vial of NADH to form the reagent solution. This ensured blank absorbance readings of 1.0 to 1.2 at $340 \mathrm{~nm}$. The final reaction concentration of NADH is $44 \mu \mathrm{g}$ in $198 \mu \mathrm{l}$.

The volume of sample taken by the Mira is approximately $80 \mu$ ] for predilution 1 in 4 with the inulinase solution. Incubation at $37^{\circ} \mathrm{C}$ follows for nearly $21 \mathrm{~min}, 50$ cycles on the Mira. From this a $50 \mu$ l aliquot was mixed with $133 \mu$ l of reagent solution. Colorimetry followed from the 4 th to the 19 th subsequent cycles.
A separate run was performed on each sample with and without Novozym in the diluent buffer. This enables a separate determination of the free fructose content prior to polyfructan hydrolysis. From the two runs the inulin or sinistrin content may be calculated. Complete assay time for inulin and free fructose concentration from 15 samples amounts to $38 \mathrm{~min}$. Two $200 \mathrm{mg} / \mathrm{l}$ fructose standards in bovine serum albumin were used as calibrators for each run. Blanks contained $150 \mu \mathrm{l}$ of the respective programme diluent, and $50 \mu \mathrm{l}$ sodium dihydrogen phosphate buffer.

When stored at $4{ }^{\circ} \mathrm{C}$, sorbitol dehydrogenase retains its activity for 14 days and Novozym 230 was active for over 6 months.

The correlation coefficients were determined by Pearson's method.

The comparison of data on the assay of fructans and fructose were analysed by linear regression. Both were calculated using a Systat 5.02 statistics programme.

\section{Results}

Our initial experiments, based on the use of an endpoint determination of sorbitol generation, with an increased path length of 1250 seconds gave poor linearities above fructose concentrations of $250 \mathrm{mg} / \mathrm{l}$ in prepared standards, despite substantial increases in sorbitol dehydrogenase concentration. By shortening the path length considerably and reducing the sorbitol dehydrogenase to examine a reaction velocity-related absorbance change, after Dalton \& Turner (5), we were able to obtain linear results up to $400 \mathrm{mg} / \mathrm{l}$ of fructose.

We found it necessary to augment the strength of the phosphate buffer to $500 \mathrm{mmol} / \mathrm{l}$ in order to reliably bring the $\mathrm{pH}$ of serum samples after dilution to near the optimal range for Novozym's chief components, $\mathrm{pH} 4.7$ (12). As a corollary, HEPES buffer also needed to be considerably stronger, to subsequently elevate the $\mathrm{pH}$ to optimal for sorbitol dehydrogenase, at 7.4 (13).

Having used linear configuration inulin as a source for standards we were able to corroborate (6) a full and linear recovery of fructose from inulin. Allowing for a $6 \%$ impurity by weight of water and non-reducing sugars (Sigma quote $2-4 \%$ water content at time of manufacture), we found $\mathrm{r}=0.999$, linear regression $\mathrm{y}=0.98 \mathrm{x}$ $+2.35 \mathrm{mg} / \mathrm{l}$, for standards from 0 to $400 \mathrm{mg} / \mathrm{l}$ in bovine serum albumin. In the presence of $50 \mathrm{mmol}$ glucose in the samples, this correlation and regression was identical.

However on changing the source of our polyfructan to sinistrin, we found a consistent recovery of only $56 \%$ of the equivalent weight of fructose. Prolonging the incubation time to minimum of two hours at room temperature was sufficient to release $107 \%$ of the equivalent weight of crystalline fructose, just short of the $111.1 \%$ appropriate to hexose hydrolysis.

After a variety of experiments with enzyme combinations capable of levanase activity (2,6-polyfructan hy- 
drolysis), we found that only a considerable excess of Novozym 230 , was sufficient to maximally hydrolyse sinistrin in the desired preincubation time of $1250 \mathrm{~s}$ on the Mira. Comparison of our fructose yields by the assay with $24 \mathrm{~h}$ manual incubations of the same samples in plasma at $22^{\circ} \mathrm{C}$ demonstrated near equivalent hydrolysis, $y=0.971 \mathrm{x}+2.78 \mathrm{mg} / \mathrm{l}(\mathrm{n}=70)$. This was unchanged by further increasing the incubation concentration of Novozym to $67.5 \mathrm{kU} / \mathrm{l}$.

After these modifications, our recovery of fructose from sinistrin against fructose standards, as analysed by linear regression was $\mathrm{y}=1.067 \mathrm{x}+0.05 \mathrm{mg} / \mathrm{l}, \mathrm{r}=1.000$, and in the presence of $54.3 \mathrm{mmol}$ glucose standards, there appeared to be a minor effect on the greater concentrations of inulinase, $y=1.053 x-1.13 \mathrm{mg} / \mathrm{l}, \mathrm{r}=1.000$.

Interassay variation for whole clearance determination on the same set of samples was satisfactory, with $\mathrm{CV}$ at $4.4 \%$ (number of sample sets $=25$, no of runs $=10$ ). Following our prospectively determined practice of rejecting results with a greater than $10 \mathrm{mg} / \mathrm{l}$ variation between any duplicate samples, the $\mathrm{CV}$ for repeated clearance determinations was $2.8 \%(n=19)$. We have determined a range of infusion clearance values in 16 healthy volunteers of 112.9 ( \pm standard deviation 16.8 ) $\mathrm{ml} / \mathrm{min}$, corrected for a surface area of $1.73 \mathrm{~m}^{2}$.

We confirmed that bovine serum albumin has a matrix effect in augmenting fructose recovery (6). With our assay this amounted to an additional $9 \%$. This appears to be attributable in part to the sorbitol dehydrogenase conversion of fructose, standards prepared in bovine serum albumin consistently showed a $6 \%$ greater absorbance change compared to those in deionised water.

Finally we found that exposure of serum samples to $62{ }^{\circ} \mathrm{C}$ for $5 \mathrm{~min}$ was sufficient to inactivate sorbitol dehydrogenase, for sample preparation for patients whose serum was likely to contain substantial quantities of it, theoretically capable of altering the kinetics of the reaction. This mainly pertains in hepatocellular disease. This brief heating did not precipitate plasma proteins or detectably hydrolyse sinistrin.

\section{Discussion}

Polyfructans are an abundant energy storage compound in plants, and the lack of a hydrolytic enzyme system in mammals render them ideal as inert markers of renal clearance. The levanbiose (levans being $\beta-2,6$-linked polyfructans) side chains found in sinistrin augment the compound's solubility, but tender it considerably less susceptible to exo- and endo-inulinase attack. Novozym's synergistic combination of 3 endoinulinases (EC 3.2.1.7), 5 exoinulinases (EC 3.2.1.80 and EC 3.2.1.26) with one enzyme of predominant invertase activity (also EC 3.2.1.26) (12, 14), is derived from Aspergillus ficuum. Some purified fungal exoinulinase and endoinulinases from another species of Aspergillus have been ineffective in cleaving levans $(14,15)$. Only more profligate varieties of exoinulinase, termed fructan $\beta$-fructosidases (EC 3.2.1.80) have levanase activity (14), and this seems to be an important discriminant in their classification. We found that a concentration 169 times greater than previously reported was necessary for maximal hydrolysis of sinistrin (6), and that description employed a 100 -fold greater concentration than had been found necessary for the complete liberation of fructose from linear inulin up to $300 \mathrm{mg} / \mathrm{l}$. Additionally we were obliged to include a prolonged incubation time, and considerably stronger buffers to ensure optimal $\mathrm{pH}$ for hydrolytic activity.

These observations underline the importance of ensuring the extent of sinistrin hydrolysis in enzymatic assays. A decrement in yield from incomplete hydrolysis might not be apparent if sinistrin standards were used as calibrators. Furthermore a differential decrement in fructose yields from plasma as opposed to urine or infusate samples, arising from a failure to adequately lower $\mathrm{pH}$ in samples with a stronger intrinsic buffering system could entail serious miscalculations of clearance.

Preliminary work suggests a very similar performance for Novo's currently available inulinase preparation Fructozyme, derived from $A$. niger.

\section{Acknowledgements}

We wish to thank Professor Christopher Pollock and Dr Neil Dalton for theoretical and methodological guidance, Mr Felix Xavier for invaluable technical assistance, Novo Nordisk for repeated help with technical data and samples and Laevosan-Austria for technical data on Inutest ${ }^{\mathrm{TM}}$, their preparation of sinistrin.

\section{References}

1. Smith H. The Kidney: Structure and function in health and disease New York: Oxford University Press, 1976:231-8.

2. Heyrovsky A. A new method for the determination of inulin in plasma and urine. Clin Chim Acta 1956; 1:470-4.
3. Bergmeyer HU. Methods of enzymatic analysis New York, London: Academic Press, 1963:156.

4. Kuehnle H, Dahl K, Schmidt FH. Fully enzymatic inulin determination in small volume samples without deproteinization. Néphron 1992; 62:104-7. 
5. Dalton N, Turner C. A sensitive and specific method for the measurement of inulin. Ann Clin Biochem 1987; 24 (1 Suppl), 24 S.

6. Summerfield AL, Hortin GL, Smith $\mathrm{CH}$, Wilhite TR, Landt M. Automated enzymatic analysis of inulin. Clin Chem 1993; 39:2333-7.

7. Wong ECC, Wilhite TR, Miller R, Smith C, Landt M. Less expensive enzymatic analysis for inulin with a kinetic assay [letter]. Clin Chem 1993; 40:1788-9.

8. Nitsch E, Iwanov W, Lederer K. Molecular characterisation of sinistrin. Carb Res 1979; 72:1-12.

9. Falbriard A, Favre H, Lucot G, Zender R. Polyfructosan, nouvelle substance glomerulaire utilisable en clinique courante. Schweiz Med Wochenschr 1969; 99:121-5.

10. Cole B, Giangiacomo J, Ingelfinger J, Robson AM. Measurement of renal function without urine collection. $\mathrm{N}$ Engl J Med 1972; 287:1109-14.

11. Schnurr E, Lahme W, Kuppers H. Measurement of renal clearance of inulin in the steady state without urine collection. Clin Nephrol 1980; 13:26-9.
12. Barrati J, Ettalbi M. Thermostable inulinases from $A$. ficuum. In: Fuchs $A$, editor. Inulin and inulin-containing crops. London: Elsevier Science Publishers, 1993:211-6.

13. Wilkinson JH. Diagnostic enzymology. UK: Edward Arnold, 1976.

14. Uchiyama T. Metabolism in microorganisms: biosynthesis and degradation of fructans. In: Suzuki M, editor. Science and technology of fructans. Boca Raton, Florida: CRC Press Inc, 1993: 169-77.

15. Uhm TB, Jeon DY, Byun SM, Hong JS, Groot Wasink JWD. Purification and properties of $\beta$-fructofuranosidase from $A$. niger. Biochim Biophys Acta 1987; 926:119-26.

Dr. C. P. R. Soper

Chemical Pathology Dept.

St Helier Hospital

Wrythe Lane

Carshalton

Surrey SM5 1AA

United Kingdom 
